\title{
Compliance and outcome of implementing World Health Organization surgical safety check list in surgical practice in a teaching hospital
}

\section{Shrestha SK 1 , Thapa $\mathrm{PB}^{2}$, Tamang $\mathrm{TY}^{3}$, Maharjan $\mathrm{DK}^{4}$}

${ }^{1}$ Suman Kumar Shrestha, Associate Professor; ${ }^{2}$ Prabin Bikram Thapa, Associate Professor; ${ }^{3}$ Tseten Yonjan Lama, Lecturer; ${ }^{4}$ Dhiresh Kumar Maharjan, Lecturer, Department of Surgery, Kathmandu Medical College Teaching Hospital, Kathmandu, Nepal

\begin{abstract}
Background: Surgical complications represent a significant cause of morbidity and mortality with the rate of major complications after inpatient surgery in industrialized countries. The purpose of this study was to summarize experience with surgical checklist use and efficacy for improving patient safety.

Objective: To evaluate the compliance of implementation and outcome of World Health Organization Surgical checklist use in surgical practice at Kathmandu Medical College.

Methods: This is a prospectively designed descriptive study including adult patients undergoing surgical procedure in Kathmandu Medical College Hospital from June 2013 till June 2014. Obtained data on compliance of World Health Organization safety checklist use by practitioner and its outcome in patient's safety were assessed using SPSS version 15. The surgeries that underwent under local anesthesia were excluded from the study.

Results: World Health Organization checklist was implemented in all 288 patients undergoing various surgical procedures with acceptable compliance by all 41 practitioners. Although it had no impact on correctable mortality and morbidity, frequent instrument malfunctions were officially recorded. Attitudes towards use of checklist was good as $100 \%$ of participants wanted use of checklist if they were having operation on themselves. However $22 \%$ of the participants complained of extra time needed to fill the checklist. Time taken to fill up sign in column of checklist was on average from 120 to 150 seconds (mean $135 \pm 5$ secs) and sign out was $80-100$ seconds (mean $95 \pm 6$ secs). Only $69 \%$ of the participants were available for sign out. Scissor malfunction was detected in $4(1.38 \%)$ cases and operation theatre table related problem was found in one case $(0.34 \%)$.

Conclusion: Implementation of World Health Organization Surgical Safety Checklist can be done with acceptable compliance and instrumental malfunction was well documented.
\end{abstract}

Key words: Checklist, Compliances, Surgery

\section{INTRODUCTION}

T The use of safety check list is to ensure consistently measurable standards in an organization including health sector'. With this background the 'Safe Surgery Save Lives' initiative was established by World Alliance for patient safety as a part of the World Health Organization effort to reduce surgical mortality all over the world². Various checklists such as Surgical Patient Safety System (SURPASS) study showed in hospital morality

Address for correspondence

Dr. Suman Kumar Shrestha

Associate Professor, Department of Surgery

Kathmandu Medical College Teaching Hospital

Sinamangal, Kathmandu, Nepal

E-mail: suman_shrestha@hotmail.com reduced from $1.5 \%$ to $0.8 \%$ around the world. However it contains 124 items to be filled and its compliance with practitioners was not well assessed ${ }^{2}$. Nepal being a developing country lacks the system of digital medical records, well equipped operation theatre and well trained operation theatre staffs. This all can modify the surgical outcome of patient especially in high patient flow centre such as our medical college. Hence, surgical safety checklist can be a tool to avoid all the mishaps that may occur in our setup. Thus this study was designed to assess the compliance to use WHO safety check list and its effect on patient safety. 


\section{METHODS}

It is a prospective descriptive study including all consecutive patients undergoing a surgical procedure under a surgical unit III of Kathmandu Medical College, department of Surgery dealing with General and GastroIntestinal Surgery from 1st June 2013 to $30^{\text {th }}$ June 2014. Ethical clearance was obtained from Ethical Committee of Kathmandu Medical College. Consent was taken and confidentiality was maintained throughout the whole study. WHO checklist is slightly modified by adding one extra first column, this column includes details of patient which was filled in waiting hall and the name tag of patient was ensured by a staff nurse. The second column was meant for confirmation of identity of the patient, site of operation, name of procedure and availability of equipments and assistants. This column also contains information about pre anesthetic check records and diagnostic results. So, the second column of the check list (sign in) was filled before induction of anesthesia by a nursing staff in operation theatre room and reviewed briefly by surgical team members and anesthetists. The third column of the checklist (Time out) was verbally confirmed and filled up by surgery resident just before skin incision. This column is used to reconfirm identity of the patient, name and site of the procedure. The role of each participant including surgeon, anesthetists, staff nurses and other OT staffs were also confirmed. The fourth column (sign out) is used for final checking of counts (instruments, needles and sponges), labeling of specimen and recording of equipment problems. This column was filled up by OT staff nurse before patient leaves operation room (Table 1).

The operating team who were practicing WHO safety checklist included surgical team members, anesthetists and nursing staffs. A questionnaire was filled up by them to assess their view regarding its importance to use this checklist. Average time taken to fill each column was calculated using a stopwatch by a staff nurse and finally patient safety outcome was analyzed using SPSS version 15 .

\section{RESULTS}

During our study period, 288 patients undergoing surgery under general anesthesia were included. The questionnaire was filled by 41 practitioners who participated to implement WHO safety checklist. Out of 41 practitioners, 10 were from surgical team, 14 from anesthesia department, 11 from nursing department and six are OT (Operation Theater) staffs in the floor. The list of participants from different departments is tabulated (Table 2).

Regarding the responses of the practitioners while using WHO checklist, it helped a lot in preventing errors in the operating room and provided a great advantage regarding communication about patient details among the members of surgery.

Responses of practitioners regarding use of surgical checklist were also tabulated. Hundred percent of the participants were convinced that they would like the checklist to be implemented on them if they needed to undergo surgery for themselves. Twenty two percent of the practitioners complained that they needed more time for implementing checklist (Table2).

The time taken to implement each column was less than 3 minutes. Minimum time taken to fill up pre procedure column was 70 seconds and maximum time taken to fill up sign column was 150 seconds. (Table 4) To assess the compliance, analysis was done about whether the checklist was filled completely. Thirty-one percent of total checklists were incompletely filled in sign out column (Table 4). However, error or near miss cases were nil. Allergy to drug and the use of prosthesis were found in two cases $(0.69 \%)$ which were not documented in an admission form. Equipment problems were encountered in twelve procedures of which cautery related were in two cases $(0.69 \%)$, hemostatic malfunctions were in three cases((1.04\%), scissor malfunction in four cases $(1.38 \%)$ suction problem in two cases $(0.69 \%)$, and OT table related problem in one case (0.34\%) (Table 5). 


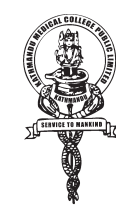

\section{KATHMANDU MEDICAL COLLEGE \& TEACHING HOSPITAL Department of Surgery SURGICAL SAFETY CHECKLIST}

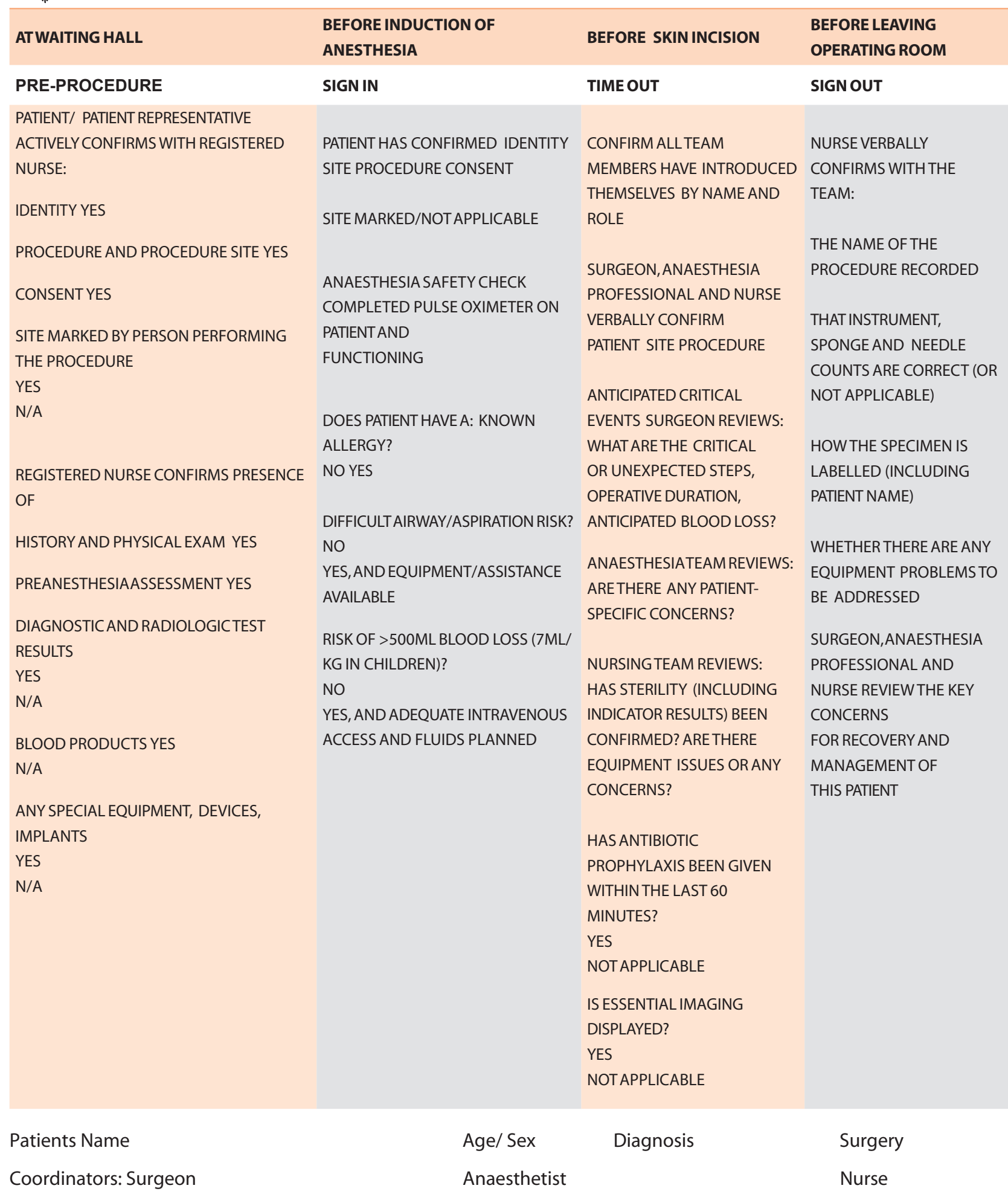


Table 2: Practitioners participating in the study $(n=41)$

\begin{tabular}{|c|c|c|}
\hline Department & Designation & Number of Participants \\
\hline Surgery & Consultant & 1 \\
\hline \multirow{3}{*}{ Anesthesia } & Resident & 5 \\
\hline & House Officer & 4 \\
\hline & Consultant & 4 \\
\hline \multirow{3}{*}{ Nursing Department(staff nurse) } & Residents & 6 \\
\hline & House officer & 4 \\
\hline & Scrub Nurse & 6 \\
\hline \multirow{3}{*}{ OT Staff(On floor) } & Preoperative ward & 4 \\
\hline & OT In-charge & 1 \\
\hline & OT Assistants & 6 \\
\hline Total & & 41 \\
\hline
\end{tabular}

Table 3: Responses of practitioners in using surgical checklist

\section{Responses of Practitioners}

The checklist was easy to use

The checklist improved operating room safety

The checklist took a long time to complete

Communication was improved through use of the checklist

The checklist may help to prevent errors in the operating room

If I were having an operation, I would want the checklist to be used
Response expressed in

Percentage

$74 \%$

$86 \%$

$22 \%$

$87 \%$

$90 \%$

$100 \%$

Table 4: Time required filling up columns of checklist

Columns of WHO safety checklist

Pre procedure

Sign In

Time Out

Sign Out
Average time taken filling up columns of checklist

$70-90$ seconds (mean $80 \pm 5 \mathrm{~s}$ )

120-150 seconds (mean $135 \pm 5 \mathrm{~s}$ )

80-100 seconds(mean $90 \pm 7 \mathrm{~s}$ )

80-110 seconds(mean $95 \pm 6 s$ )

Table 5: Compliance of Practitioners to fill up checklist columns and associated problems detected via the use of WHO checklist

$\begin{array}{lccc}\text { Column of WHO checklist } & \begin{array}{c}\text { Percentage of completeness } \\ \text { of filling checklist columns }\end{array} & \begin{array}{c}\text { Associated problems } \\ \text { Detected }\end{array} & \begin{array}{c}\text { Number of cases with } \\ \text { problems }\end{array} \\ \text { Pre procedure } & 100 \% & \text { Allergy to drug and use of } & \text { prosthesis } \\ \text { Sign in } & 100 \% & \text { Cautery } & 2(0.69 \%) \\ \text { Time out } & 100 \% & \text { hemostatic malfunction } & 2(0.69 \%) \\ \text { Sign out } & 69 \% & \text { Scissor malfunction } & 3(1.04 \%) \\ & & \text { Suction problem } & 4(1.38 \%) \\ & & \text { OT table related problem } & 1(0.69 \%)\end{array}$

Total: 14 out of 288 


\section{DISCUSSION}

As in the field of aviation industry, in surgical practice also, to improve surgical quality and safety, checklists are introduced ${ }^{2}$. WHO has proposed the checklist for surgical procedure to improve team work and to build confidence by decreasing avoidable errors. This is the era in which reality check is a must for all the patients rather than for most of the patients.

The fourth column (sign out) of the checklist was only completed in $69 \%$ due to tiredness, time limit and only doing verbal confirmation rather than taking written confirmation. A simple practice of administration of prophylactic intravenous antibiotic preoperatively reduces surgical site infection ${ }^{4}$. In our study, all cases were administered prophylactic preoperative single dose antibiotics which was confirmed, guaranteed as well as documented in the checklist.

Surgeons, anesthetists, nurses and operating theatre staff who completed the checklist wanted the checklist to be used while undergoing surgery of their own. Only enforcing the use of checklist might not be effective, these can be modified as required on institutional basis and also requires the strong desire of its use ${ }^{5}$. The study might be affected by Hawthorne effect as criticized in other studies as the observer in the study might modify the response as per outcome required ${ }^{6-7}$.

Though, these numbers of data are not sufficient to provide solid inference, we can conclude this checklist as a supplementary tool with good compliance.

\section{CONCLUSION}

A surgical checklist is a simple and promising strategy for addressing surgical safety worldwide. Our results support the WHO's recommendation to use the Surgical Safety Checklist in all the operative procedures. The checklist should be understood not merely as a list of items to be checked off, but it should be used as an instrument for the improvement of communication, teamwork and safety culture in the operating room and it should be implemented accordingly in our setting.

\section{REFERENCES}

1. Russ S, Rout S, Caris J, Mansell J, et al. Measuring variation in use of the WHO surgical safety checklist in the operating room: a multicenter prospective cross-sectional study. J Am Coll Surg. 2015;22(1):111.

2. deVries EN, Dijkstra L, Smorenburg SM, et al. The surgical Patient Safety System(SURPASS) checklistoptimizestimingofantibioticprophylaxis. PatientSafSurg.2010;4:6.

3. Gawande A. The Checklist Manifesto: How to Get Things Right. New York: Metropolitan Books; 2010.32 p.

4. Classen DC, et al. The timing of prophylactic administration of antibiotics and the risk of surgical wound infection. New England Journal of Medicine. 1992;326:281-6.

5. Bosk CL, Dixon-Woods M, Goeschel CA, Pronovost PJ. Reality check for checklists. Lancet.2009;374:444-45.

6. Haynes AB, Weiser TG, Berry WR, etal. A surgical safety check list reduce morbidity and mortality in a global population. NEnglJMed.2009;360:491-99.

7. Mc Cambridge J, Kypri K, Elbourne DR. A surgical safety checklist. NEnglJMed.2009;360:2373-74. 